\title{
A low-cost autonomous rover for polar science
}

\author{
Andrew O. Hoffman ${ }^{1,3}$, Hans Christian Steen-Larsen ${ }^{2}$, Knut Christianson $^{3}$, and Christine Hvidberg ${ }^{1}$ \\ ${ }^{1}$ Centre for Ice and Climate, Niels Bohr Institute, University of Copenhagen, Juliane Maries vej 30, \\ Copenhagen 2100, Denmark \\ ${ }^{2}$ Geophysical Institute, University of Bergen and Bjerknes Centre for Climate Research, Bergen, Norway \\ ${ }^{3}$ Department of Earth and Space Sciences, University of Washington, Seattle, Washington 98195, USA
}

Correspondence: Andrew O. Hoffman (hoffmaao@uw.edu)

Received: 19 December 2018 - Discussion started: 2 January 2019

Revised: 4 April 2019 - Accepted: 5 May 2019 - Published: 11 June 2019

\begin{abstract}
We present the developmental considerations, design, and deployment of an autonomous modular terrestrial rover for ice-sheet exploration that is inexpensive, easy to construct, and allows for instrumentation customization. The total construction cost for this rover is less than USD 3000, approximately one-tenth the cost of existing platforms, and it can be built using facilities frequently available at academic institutions (machine shop, 3-D printer, open-source hardware and software). Instrumentation deployed on this rover can be customized; the rover presented in this study was equipped with a dual-frequency GPS receiver and a digital SLR camera for constructing digital elevation models using structure-from-motion (SfM) photogrammetry. We deployed this prototype rover on the Northeast Greenland Ice Stream to map local variations in snow accumulation and surface topography. The rover conducted four autonomous missions based out of the East Greenland Ice-Core Project (EastGRIP) camp during July 2017, measuring surface elevation transects across the hazardous ice-stream shear margins. During these missions, the rover proved capable of driving over $20 \mathrm{~km}$ on a single charge with a drawbar pull of $250 \mathrm{~N}$, sufficient to tow instrumentation of up to $100 \mathrm{~kg}$. The rover also acquired photographs that were subsequently used to construct digital elevation models of a site monitored for spatiotemporal variability in snow accumulation, demonstrating adequate stability for high-resolution imaging applications. Due to its low cost, low-power requirements, and simple modular design, mass deployments of this rover design are practicable. Operation of the rover in hazardous areas circumvents the substantial expense and risk to personnel associated with conventional, crewed deployments. Thus, this rover is an investigatory plat-
\end{abstract}

form that enables direct exploration of polar environments considered too hazardous for conventional field expeditions.

\section{Introduction}

Despite the recent proliferation of autonomous platforms (airborne drones, extraterrestrial rovers, and even autonomous vehicles), deployment of conventional autonomous vehicles in polar regions remains challenging due to the hostile environment, stringent low-power requirements, and limits on construction costs (compared with, for example, extraterrestrial rovers). Temperatures in polar regions routinely drop below $-40^{\circ} \mathrm{C}$, well below the temperature ratings of conventional electronics, and wind speeds can easily exceed $20 \mathrm{~m} \mathrm{~s}^{-1}$, inducing variable stresses on any large profile robotic platform. As sunlight is often completely absent for several consecutive months, rover designs that leverage solar power are only viable during the summer, precisely when there are often already field personnel present capable of conducting similar measurements. Although precipitation is low over the interior of the ice sheets, ubiquitous drifted snow can infiltrate the chassis, where subsequent snowmelt due to heat from powered components can then damage electronic components designed to remain dry. Drifted snow also forms sastrugi and other large snow bedforms, introducing a complex and time-variable topography of variable gravitational resistance, which presents a challenge for any robotic assembly designed to drive across the surface of the ice sheet. Because of these environmental challenges, very few autonomous robotic exploration platforms have been built and successfully deployed to survey the po- 
lar ice sheets. Of these systems, NASA's rover, "GROVER" (Trisca et al., 2013; Robertson et al., 2013), and the Cold Regions Research and Engineering Lab platforms, "Yeti" and "Cool Robot", are the only non-combustion rovers actively conducting polar science (Lever et al., 2013; Lever et al., 2006). The high fabrication cost of these rovers is, however, an impediment to the construction of multiple rovers that would lead to extensive deployments, as each requires over USD 10000 in materials alone. Less expensive, expendable rovers have been developed for military, police, and rescue operations (Weisbin et al., 1999; Maddux et al., 2006; U.S. Department of Defence, 2013), but these tactical autonomous robots have been deployed in highly variable urban terrain with instruments and drive systems designed for that specific application (Blitch, 1998), and they are not well-suited for polar environments.

Here we present the design, construction, and deployment of a largely autonomous, low-cost, modular rover that can expand ice-sheet science programs in duration and extent without straining budgets or exposing personnel to risk. The rover we built was intended to enhance the surface science capabilities at the East Greenland Ice-Core Project (EastGRIP) camp; thus, although designed for general operation in an ice-sheet interior, the instrumentation was customized to conduct surface and near-subsurface measurements, including SfM photogrammetry, aerosol and isotope sampling, and snow accumulation radar. Our simple, low-cost design makes the rover built at the Centre for Ice and Climate, hereafter termed the "CIC rover", truly expendable and opens up new possibilities for coordinated autonomous multi-rover surface science. In this paper, we detail the mechanical, software, and instrumentation considerations for the CIC rover, present the rover's performance during an exploratory field deployment on the Northeast Greenland Ice Stream, and, finally, discuss the outlook for widespread construction and deployments of variants of the CIC rover for other applications.

\subsection{Polar rover research}

Early polar rover research for glaciological science has been well characterized by Lever et al. (2013) and Ray et al. (2007). Together, these groups built the first two autonomous battery-powered polar science rovers, both designed with the goal to image internal ice structure in Greenland and Antarctica by pulling ground-penetrating radar. The Yeti rover has been used successfully on traverses and can image and detect bridged crevasses in real time, warning traverse teams of immediate subsurface dangers along the route. The Yeti platform has collected more published data than any other rover platform even with a limited $20 \mathrm{~km}$ mission range, but the platform has been underutilized in science investigations outside of englacial imaging along traverse routes because of its finite range. The Cool Robot boasts significant software enabled autonomy and is there- fore capable of traversing $>100 \mathrm{~km}$ across the ice sheets in the polar summer while communicating via iridium satellite with off-ice operators. Since the development of these two autonomous rovers, Yeti and Cool Robot, NASA has built the Goddard Remotely Operated Vehicle for Exploration and Research (GROVER), which has been used to image the nearsurface firn in the vicinity of Summit Camp, Greenland, at high vertical resolution $(\sim 2 \mathrm{~cm})$ to understand recent distributed accumulation (Trisca et al., 2013; Robertson et al., 2013). The system proved useful for monitoring snow and firn processes, but it has not been deployed since 2013. These systems set the current standard for rover science in the polar regions, but they remain underused by glaciological field research teams today due to their expense and the operational expertise required to propose robot enabled polar science and deploy existing polar robots. Other rover deployments in polar regions have been aimed at testing designs of extraterrestrial rovers, rather than collecting scientific data on the polar regions of this planet. For example, NASA deployed their "Tumbleweed" rover out of Summit Camp, Greenland. These spherical rovers minimize power requirements by relying on near-surface wind to transport them across the ice sheet. However, this locomotion mechanism enables serendipitous rather than targeted discoveries, as many of the most scientific interesting regions of ice sheets are not likely to be explored by rovers transported primarily by prevailing katabatic winds (Behar et al., 2004). Instrumentation on these rovers was also solely aimed at determining the efficacy of wind transport, i.e., GPS for location and satellite for communication. More recently, autonomous rovers designed by the Chinese National Antarctic Research Program have successfully been used to image crevasses in real time with an intriguing, but unpublished, design that includes vertical axis wind turbine power technology. This rover proved capable of traveling several hundred kilometers on a $58 \mathrm{~d}$ deployment, but it has not yet been used for follow-on missions.

\subsection{Opportunities enabled by modular rover design}

None of the aforementioned rovers have been deployed on missions beyond their original project scope (crevasse detection and mapping of internal layers with radar), and the cost to design and deploy polar rovers has remained much higher than the number of equivalent person-hours required to conduct the same volume of work, as the rovers themselves often require the support of crewed camps. This is principally due to the lack of widespread rover use beyond the personnel involved in their original design; because the rovers are customized, they have a high barrier to use by external personnel. Widespread use and integration of rovers into polar science requires a new approach that motivates our principal rover science goal: to build a modular rover that could be repurposed to collect observations germane to a variety of polar science programs in the future. This overarching objective set both our drive design and scientific instrumentation 
goals. We seek to build a rover capable of $>10 \mathrm{~km}$ traverses on a single battery charge with the capacity to tow $100 \mathrm{~kg}$ in science payload that could be modified to incorporate a vertical axis wind turbine or solar panel array as the autonomy of the rover is further developed. We also aim to design a rover that accommodates a wide variety of scientific goals, including mapping snow, firn, and ice internal stratigraphy, observing boundary layer meteorology, and sampling snow. Our rover design is also inexpensive, so that several rovers could be deployed out of a single camp to collect linked scientific measurements using ground-penetrating radar and SfM cameras to conduct more comprehensive surveys of surface and bed topography that are focused on regions where the rovers identify uncharacteristic bed reflectivity or bed roughness. First, we detail the mechanical and software design of the rover system. We then demonstrate the rover's measurement capabilities with a summary of field operations in northeast Greenland and conclude by discussing how this system could be used in the future fieldwork to understand feedbacks between surface and bed topography and ice flow via mapping internal layer structure.

\section{Rover design}

Building a polar rover capable of driving long distances over an ice sheet requires a careful ledger of total traction and resistance associated with driving in snow. The drive mechanics originally developed for extraterrestrial rovers have been adapted for use in other polar rover designs to ensure platform mobility and efficiency on snow. We first detail the predicted mobility of our polar rover design by conceptually describing, then calculating, the dominant resistance forces our rover may encounter and the traction we predict for a $100 \mathrm{~kg}$ system operating in soft snow. We then describe how this design informed build decision making and fabrication. Finally, we summarize the mechanical design with a parameter table comparing designed and measured rover capability.

\subsection{Predicted mobility design}

We based the mobility design of the CIC rover on Bekker locomotion theory for vehicles manoeuvring over deformable surfaces (Bekker, 1962). The Bekker theory, which was first applied to lunar rover design in the 1960s, aims to represent empirical relations for wheel-surface contact physics to quantify wheel traction and resistance as a wheel compresses an underlying surface. Rover mobility can be characterized by the platform's drawbar pull, or the difference between the rover's surface traction and motion resistance, which defines the ability of the vehicle to move over a given terrain. In the context of ice-sheet exploration, motion resistance acting in opposition to the snow surface traction can be separated into three distinct contributions: work done by the rover to compact the snow surface $\left(R_{\mathrm{c}}\right)$, internal friction across the
Table 1. Table of parameters used in Bekker locomotion equations (Bekker, 1962), and the values used to parameterize rover resistance, traction, and mobility. Snow cohesion parameters $\left(n, k_{1}, k_{2}\right.$, $\phi$ ) vary widely depending on the temperature and humidity as snow precipitates, and also depend on the time between snowfall events as the snow settles and metamorphizes reducing the separation between single grains and increasing the bulk density of the medium. The chosen parameters represent dry, low-density polar snow corresponding to cold snow $\left(<10^{\circ} \mathrm{C}\right)$ after a particularly large snow-fall event. These conditions promote deep sinking and represent a conservative estimate of the necessary traction for mobility.

\begin{tabular}{llr}
\hline Parameter & Description (for rover in snow) & Typical value \\
\hline$k_{1}$ & Modulus of snow cohesion & $0.2 \mathrm{~N} / \mathrm{cm}^{n+1}$ \\
$k_{2}$ & Modulus of snow friction & $0.1 \mathrm{~N} / \mathrm{cm}^{n+2}$ \\
$l$ & Width of wheel & $12.7 \mathrm{~cm}^{\mathrm{a}}$ \\
$z_{0}$ & Total depth of sinkage & $1.3 \mathrm{~cm}^{\mathrm{b}}$ \\
$n$ & Pressure sinkage exponent & $0.9-1.2$ \\
$D$ & Diameter of wheel & $37 \mathrm{~cm}^{\mathrm{a}}$ \\
$c_{\mathrm{f}}$ & Internal friction coefficient & $0.05-0.10$ \\
$\phi$ & Snow wheel friction angle & $30-60^{\circ}$ \\
$s$ & Wheel slip ratio. & 0.02 \\
\hline
\end{tabular}

${ }^{a}$ Value specific to CIC rover design. ${ }^{b}$ Value follows from choice of parameterization.

drive system $\left(R_{\mathrm{r}}\right.$; motor inefficiency, friction between the tire and rim hub, bearing friction, etc.), and gravitational resistance encountered when the rover navigates slopes $\left(R_{\mathrm{g}}\right)$. Building on the success of existing polar rovers (Lever et al., 2006), we chose to implement a similar design: a four-wheel drive (4WD) rover over a skid-steer design. The 4WD-in-hub motor system makes the assembly more modular, allowing for more efficient but complicated and expensive two-track systems to be implemented in future iterations of the rover design. To minimize shipping costs and enable deployment with minimal support (all components can be easily moved by a single person), we constrained the total designed rover weight to be less than $100 \mathrm{~kg}$. We use force-balance analysis of wheel pressure assuming a rover weight of $\sim 1000 \mathrm{~N}$ equally distributed across four tires (shown in Fig. 1) to develop equations for resistance from rover sinkage and compaction due to the overburden force on the tire. The parameters used in our analysis are summarized in Table 1. Following Bekker (1962), we assume that snow responds to the applied pressure of a rover wheel as a nonlinear spring:

$P=\left(k_{1}+\frac{k_{2}}{l}\right) z_{0}^{n}$,

where $P$ is the applied pressure from the wheel, $l$ is the width of the wheel, $z_{0}$ is the final depth that the wheel sinks into the snow, $k_{1}$ is the modulus of cohesion of snow deformation, $k_{2}$ is the modulus of friction of snow deformation, and $n$ is a heuristic parameter that captures stress dependence of snow deformation (Bekker, 1962). The force resisting rolling mo- 


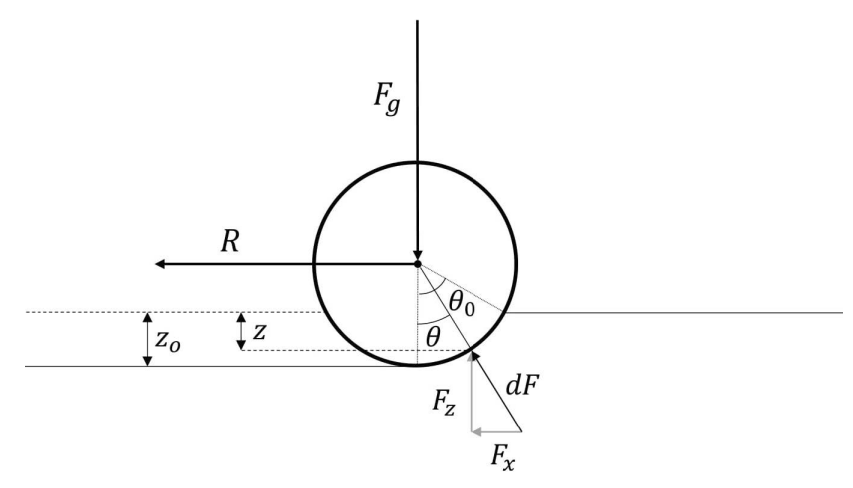

Figure 1. Schematic of a wheel compressing snow as it drives over a smooth surface. $F_{\mathrm{g}}$ is the overburden force due to gravity acting on the chassis and rover wheel, $R$ is the resistance force felt from compaction and internal friction, $z_{0}$ is the depth the rover sinks into the ground, and $\theta_{0}$ and $\theta$ are the angles which become important for integrating the traction around wheel.

tion of a wheel with diameter $D$ due to snow compaction $R_{\mathrm{c}}$ can be related to the normal force at the interface and then the force of gravity resulting in the following equation:

$$
\begin{aligned}
R_{\mathrm{c}} & =\frac{\left(k_{1}+\frac{k_{2}}{l}\right)}{n+1} z_{0}^{n+1}=\frac{l \cdot\left(k_{1}+\frac{k_{2}}{l}\right)}{n+1} \\
& \left(\frac{3}{3-n} \cdot \frac{F_{\mathrm{g}}}{l\left(k_{1}+\frac{k_{2}}{l}\right) \sqrt{D}}\right)^{\frac{n+1}{n+\frac{1}{2}}}=15 \mathrm{~N} \text { per wheel }
\end{aligned}
$$

with the parameter values assigned in Table 1. Compaction resistance is often assumed to dominate other resistance forces, such as rolling resistance aggregated across all sources of internal friction from the tires and bearings as well as gravitational resistance encountered when the rover traverses up topographic gradients (Lever et al., 2006). Sastrugi, although common, rarely exceed slopes of $15^{\circ}$; however, gravitational resistance may become a more important resistance force in regions with more dynamic topography. For our rover, we assume that rolling resistance, $R_{\mathrm{r}}$, from bearing friction and slip at the wheel-hub interface scales with the weight of our assembly but represents less than $2 \%$ of the total resistance and $10 \%$ of the gravitational resistance associated with climbing small sastrugi, $R_{\mathrm{g}}$.

$R_{\mathrm{r}}=F_{\mathrm{g}} c_{\mathrm{f}}=5 \mathrm{~N}$ per wheel

$R_{\mathrm{g}}=F_{\mathrm{g}} \cdot \sin \left(\phi_{\max }\right)=64 \mathrm{~N}$ per wheel,

where $c_{\mathrm{f}}$ is the total coefficient of friction for wheel and bearing inefficiencies (typically $<0.05$ ), and $\phi_{\max }$ is the angle of the slope the rover climbs as it moves across the ice sheet. In our design, we neglect bulldozing resistance, which occurs as snow is displaced in front of the rover's advancing wheels and depends on snow cohesion and wheel geometry. Narrow wheels reduce bulldozing resistance by significantly increasing the ratio of snow that is displaced to the sides of the rover wheel versus the snow that is pushed forward in front of the wheel; however, with narrower wheels the rover sinks deeper into the snow. Because the sinkage depth of the wheels relative to the wheel diameter is greater than $6 \%$, we can assume that bulldozing can be neglected in the force-balance calculation (Ishigami et al., 2007).

For a four-wheel model, we anticipated that the dominate resistance forces come from wheel sinkage on the front wheels and gravitational resistance as the rover traverses in and out of the shear-margin troughs of the northeast Greenland ice stream, where steeper surface slopes occur. A conservative estimate of the total resistance force is

$R_{\mathrm{tot}}=\left(R_{\mathrm{c}}+R_{\mathrm{r}}+R_{\mathrm{g}}\right)=326 \mathrm{~N}$.

The dimensionless resistance parameter our rover must overcome to move across the most extreme conditions of the Greenland ice sheet interior is

$\frac{R}{F_{\mathrm{g}}}=0.33$.

This value is noticeably larger than the estimates produced by Lever et al. (2013) and Ray et al. (2007) due to the higher estimate for gravitational resistance and the heavier anticipated weight. This value represents an upper bound on the resistance forces, as we will see when we compare it to values measured during the field deployment. The Bekker locomotion model also uses the relationship between the tire and snow surfaces and the shearing strength of the tire motion to predict vehicle mobility. The shearing strength at the wheel snow interface can be described by the horizontal rover traction:

$R=\left(A \cdot C+F_{\mathrm{S}} \tan \phi\right) \cdot\left(1-\frac{K}{l}\left(1-e^{-\frac{s l}{K}}\right)\right)$,

where $A$ is the contact area of the tire with the snow, $C$ is the snow-wheel cohesion, $\phi$ is the snow-wheel friction angle, $s$ is the wheel slip ratio, $K$ is the coefficient of slip, $l$ is the length of the contact path, and $\mathrm{D}$ is the diameter of the wheel, $\frac{D}{2} \cos ^{-1}\left(1-\frac{2 z}{D}\right)$. Values for these parameters come from vehicle tests at Summit Station, Greenland (Army Corps of Engineers, 1972). The dimensionless form of the drawbar pull, DP, which captures the effective traction, and the load we could pull with the rover takes the following form:

$\frac{\mathrm{DP}}{F_{\mathrm{g}}}=\frac{T-R}{F_{\mathrm{g}}}=0.29$,

where $T$ is the traction at the snow-wheel interface, $R$ is the total resistance, and $\frac{\mathrm{DP}}{F_{\mathrm{g}}}$ is the dimensionless efficiency metric of the rover we calculate using parameters for the predicted CIC rover design. The predicted drawbar pull suggests that the CIC rover can pull a sled with $80 \mathrm{~kg}$ of freight using just 
$120 \mathrm{~W}$ of power, which is more than adequate cargo capacity to tow a ground-penetrating radar at least $10 \mathrm{~km}$ under the efficiency and energy density constraints of inexpensive sealed lead acid batteries.

\subsection{Chassis and wheel design}

The CIC rover design is also compact, because the entire system was built to ship inside two $80 \mathrm{~cm} \times 60 \mathrm{~cm} \times 61 \mathrm{~cm}$ shipping containers. We designed the chassis to come apart in four pieces that can be assembled into the rover body and an accompanying lid that protects the electronics, motors, and controllers from the external environment. Stainlesssteel axles were cut with collars that interface directly with four brushless DC motors using dual screw keys. These collars protect the fixed rover motors from bearing radial torques that could damage the motor shafts. Coupling the motors to the stainless-steel axles are four planetary gears with gear ratios of 1:77, which were chosen to produce sufficient torque at the wheel to overcome all predicted resistance forces. Because of the cost and limited redesign capabilities of standard wheel-rim-axle assemblies, we printed polyethylene rover rims with the Ultimaker 3 extended 3-D printer. These rims hugged four ATV snow tires that remained at carcass pressure with a wheel diameter of $0.38 \mathrm{~m}$. The four brushless DC motors propel the rover, operating near their max speed of $3000 \mathrm{rpm}$ with a nominal torque of $0.4 \mathrm{Nm}$ before the planetary gearbox. After the gearbox, the motors supply a nominal torque of $26 \mathrm{Nm}$ rotating at $39 \mathrm{rpm}$. Assuming that the tires deform to effective diameter of $\sim 36 \mathrm{~cm}$ under the weight of the rover, the top speed of the rover is

$V_{\max }=\frac{39 \mathrm{rpm}}{60 \mathrm{~s}} \cdot 2 \pi \cdot 0.19=0.77 \frac{\mathrm{m}}{\mathrm{s}}$.

The motor controllers are modulation servo amplifiers fixed using $5 \mathrm{~V}$ square wave signals across analog pins of an Arduino MEGA microcontroller. Undervoltage (below $18 \mathrm{~V}$ ) and overheating (above $95^{\circ} \mathrm{C}$ ) emergency switches protect the controllers and override the microcontroller in case of electrical load depletion or internal malfunction. The rover signals the motor controllers from the Arduino MEGA to navigate. The rover turns by reducing the rotation speed of wheels on the same side of the chassis as the turn direction. The movement is equivalent to the skid steering of a tracked vehicle (i.e., tanks) except that the wheels themselves are coupled via the speed controller signalling, and not mechanically linked with treads.

Besides our choice of motors, the drive system we designed was also built to operate in the low temperatures found in polar regions. Using grey styrofoam, we insulated two $12 \mathrm{~V}, 70 \mathrm{amp}$ hour sealed lead acid gel-cell batteries wired in series to power the assembly, keeping the lead acid batteries above freezing at all times to enhance battery efficiency. Our rover design does not include active heating elements, which could be added and powered by the existing power bus

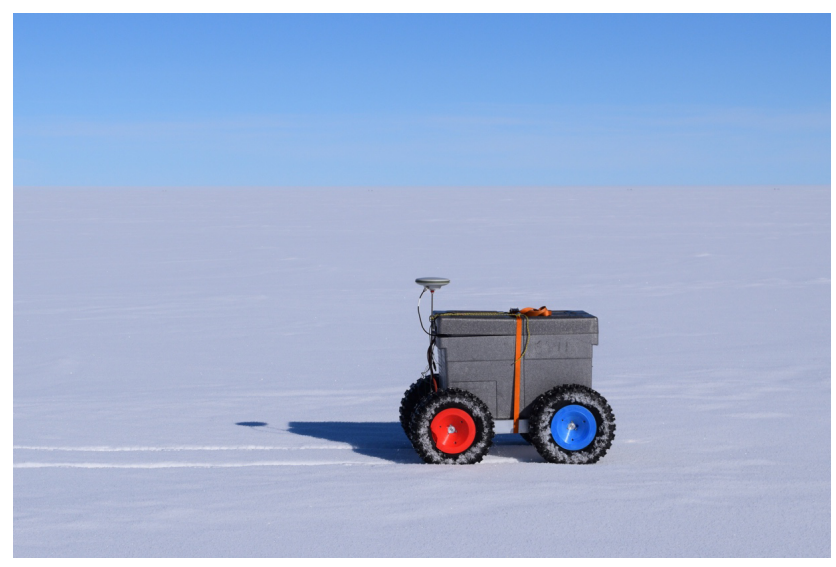

Figure 2. Photograph of the CIC rover taken on 4 July 2017 during its first mission out of the EastGRIP camp. The rover was able to pull three cargo boxes and a person, a weight of nearly $170 \mathrm{~kg}$, in a low-friction plastic sled in untouched snow. This weight is more than twice that of common commercial ground-penetrating radar systems, which could be towed behind the rover to map accumulation layers.

to ensure mobility when insolation is low (i.e., during polar winter) or when temperatures inside the insulated the styrofoam chamber drop below $0{ }^{\circ} \mathrm{C}$. All other rover parts were purchased to perform at their designed specifications in temperatures above $-10^{\circ} \mathrm{C}$; however, tests during the summer in Greenland proved that the rover was fully operational at temperatures as low as $-23^{\circ} \mathrm{C}$. Future work in the Greenland spring or late summer will test the low-temperature limit for continuous, reliable operation.

\subsection{Software, navigation, and instrumentation}

During a mission, the rover may be directed to make and log several different measurements. The navigation and measurement sampling algorithms must have the ability to set appropriate different priorities during these missions. As the rover powers, the microcontroller first runs an initializing set of commands that are contained within a C-programmed initialization script. These commands establish connections between the microcontroller and the GPS module and the micro-SD card, test that all motors and motor controllers are connected, and calibrate the power sent to all wheels so that the rover can drive in the straightest path. The initialization script is followed by the primary loop that executes navigation commands and communications with external instruments and hardware. The structure of the primary loop follows a hierarchy of hardware checks and instrument sequences centered around a query to the onboard GPS to establish the rover position every second. A serial port military connector in the chassis rear wall allows for manual rover control, while a dual-frequency GNSS receiver (Leica GNSS 1200) allows the rover to navigate to waypoints loaded to 
Table 2. Summary of CIC rover design parameters and measured performance in the field.

\begin{tabular}{lrr}
\hline Rover specifications & & \\
\hline Parameter & Design specification & CIC rover \\
\hline Rover mass & $<100 \mathrm{~kg}$ & $85 \mathrm{~kg}$ \\
Pulling force $(\mathrm{N})$ & 300 & 250 \\
Dimension $\left(\mathrm{m}^{3}\right)$ & $<1$ & $0.7 \times 0.7 \times 0.6 \mathrm{~m}\left(0.3 \mathrm{~m}^{3}\right)$ \\
Wheel radius $(\mathrm{cm})$ & 20 & 18 (fully inflated) \\
Speed $\left(\mathrm{m} \mathrm{s}^{-1}\right)$ & - & 0.77 \\
Run time (hours) & 8 & 12 \\
Path tolerance $(\mathrm{m})$ & \pm 5 & \pm 7 \\
Minimum temperature $\left({ }^{\circ} \mathrm{C}\right)$ & -20 & -23 (lowest temperature encountered) \\
Dimensionless resistance R/W & 0.33 & 0.14 \\
Cost & USD 3000 & USD 2900 \\
\hline
\end{tabular}

the rover via the micro-SD card prior to initialization. In the main loop of the navigation and instrument triggering algorithm, an interrupt key can be pressed to switch between autonomous drive mode and user navigation mode, which is the default. During a cold start, the receiver must parse time, position, and almanac clock corrections from each satellite, so for an initial run, the rover waits $5 \mathrm{~min}$ to constrain its initial position before manoeuvring to the first waypoint. Initially, while the rover is manually controlled, turning, rover acceleration, and instrument triggering are all initiated via the USB-port. During an autonomous mission, the rover uses a haversine algorithm to calculate the distance and bearing from the rover's current position to the next waypoint. The distance to the next waypoint can be determined from the rover's current position (lat 1 , long 1 ) and the proximal waypoint position (lat 2 , $\operatorname{long}_{2}$ ), and a calculation of the bearing in degrees from north follows from the distance to the next waypoint:

$d=2 \arcsin$

$\sqrt{\cos \left(\operatorname{lat}_{1}\right) \cdot \cos \left(\mathrm{lat}_{2}\right) \cdot\left(\sin ^{2} \frac{\left(\operatorname{long}_{1}-\operatorname{long}_{2}\right)}{2}\right)+\sin ^{2} \frac{\left(\mathrm{lat}_{1}-\mathrm{lat}_{2}\right)}{2}}$

bearing $=\arccos \frac{\left(\sin \left(\mathrm{lat}_{2}\right)-\sin \left(\mathrm{lat}_{2}\right) \cdot \cos (d)\right)}{\sin (d) \cdot \cos \left(\mathrm{lat}_{1}\right)}$

The navigation bearing is the corrected course the rover travels based on the great circle path from the rover's current position to the next waypoint using the rover's current position and a linear average of the rover's bearing since the last correction. From the corrected bearing and distance to the next waypoint, the rover turns towards the waypoint if the difference between the current bearing and the corrected bearing exceeds $5^{\circ}$. In both manual and autonomous drive modes, the rover turns by signalling motors synchronously on the turn-direction side of the chassis to slow down by a preset percentage of the drive speed depending on the bearing difference. In autonomous drive mode, the rover derives a bearing from the difference between the two previous po- sitions every $3 \mathrm{~s}$. This GPS positioning information is also used to fit a line for rover velocity from the 10 previous GPS readings. If the velocity from the linear fit to displacement is less than the expected value based on signalling from the motor controllers, the rover will slow down. The microcontroller will eventually re-signal the motor controller to speed up when the velocity of the rover is consistent with the measured velocity from GPS. If the wheels begin to slip at the snow interface, the rover can slow down and regain traction. When the rover reaches the final waypoint, it stops powering the drive assembly, but continues to take GPS measures that could be used in a radio-telemetry script to expedite rover retrieval. The measurement sampling frequency and GPS turning correction frequency are initialized in the setup script to user input values. For the CIC rover, they were set at 3 and $20 \mathrm{~s}$, respectively, and were based on requirements for the SfM photogrammetry.

The software and instrument design we have chosen is also modular and could be changed as we further develop the rover's autonomous capabilities. For example, the navigation protocol presently consists of uploading predetermined waypoint paths directly to the system before the rover embarks on a mission. This simple procedure could be expanded to incorporate live instrument data (i.e., surface photos, radar imagery) as real-time input into an artificially intelligent navigation system that would learn and adapt to a specific research setting and science objective. As proof of concept for the rover's autonomous capabilities, we next present a workflow for automated ground-based SfM photogrammetry, which in future iterations of the rover design could be used to build real-time elevation maps that could be incorporated into rover navigation.

\subsection{Instrumentation: close-range photogrammetry}

We chose not to design instruments specifically for the summer 2017 rover deployment. We hope to provide a platform that can support different instrumentation for a variety 
of scientific goals and seek to develop that framework instead of creating instrumentation solely for science specific to EastGRIP. For our test deployment, we focused on developing surface elevation mapping capabilities via structurefrom-motion photogrammetry, which could serve many scientific and operational goals, by installing a dual-frequency GNSS receiver and digital single-lens reflex camera (Nikon D3100) on the rover. The SfM camera selected for initial testing of the rover instrumentation was mounted and wired to the microcontroller in the field and is primarily meant to demonstrate the signalling capabilities of the rover and the platform's utility for linked surface and atmosphere studies. Scientifically, there is a long history of measuring relative snow and ice elevation using photogrammetry. Baltsavias et al. (2001) provide a historical review on glacier monitoring and used automated digital elevation model extraction tools based on photogrammetric area correlation to generate elevation models of Unteraargletscher, Switzerland. The SfMderived elevation model matched one derived from airborne laser scanning data, except in areas where the spatial contrasts and variations in color and light intensity were low. In the ice-sheet interior, centimeter-scale vertical resolution elevation maps of surface roughness derived from stereo-image pairs can be used to better understand sastrugi evolution and can be coupled with ground-penetrating radar mapped snow stratigraphy and water isotope measurements to better understand the influences of surface topography on snow densification, ice flow, and surface isotope deposition and fractionation. In low accumulation environments, such as central Greenland, snow bedform evolution may control spatial variations in accumulation and isotopic composition of snow and firn near the surface. Over long timescales (and related depth-age scales in the ice) these signals are smoothed, but they could have implications for interpreting shallow icecores. For these reasons, the rover was taken to the EastGRIP camp for field evaluation and integration into future surface science projects.

\section{Experiments and results}

Rover performance was evaluated in northeastern Greenland (Fig. 3) where we tested the rover's dimensionless resistance, the signalling capabilities for instrument measurements, the total distance the rover could travel, and the resolution of rover photogrammetric methods. The rover was deployed out of the EastGRIP camp during the month of July 2017. During this time, three precipitation events allowed us to test the rover's performance in both drifted and compacted snow conditions. The rover successfully completed four $20 \mathrm{~km}$ missions from camp, navigating within $7 \mathrm{~m}$ of the prescribed waypoint path. Inefficiencies in the rover directional control due to motor controller current drift forced subtle drive corrections every $20 \mathrm{~m}$ to keep the rover on course, which made the rover's actual travel path between waypoints, at times,

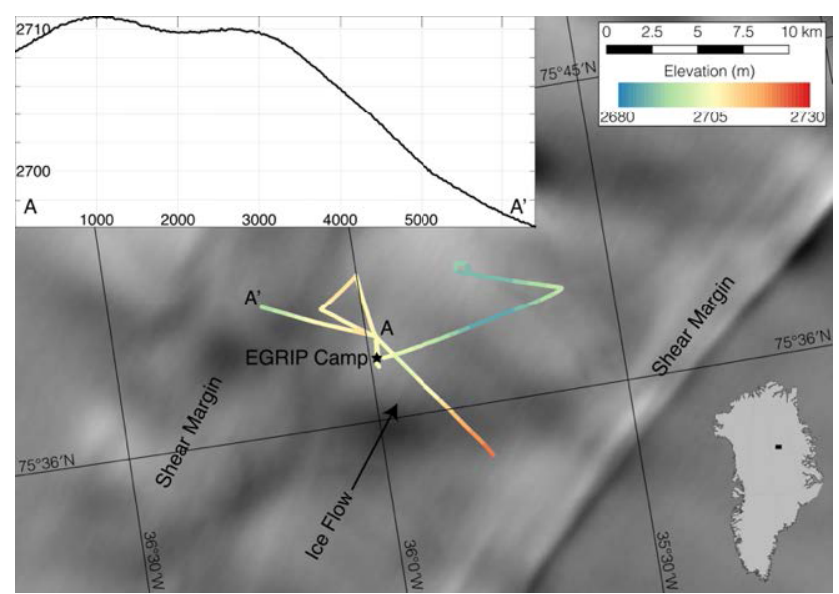

Figure 3. MODIS image of the Northeast Greenland Ice Stream and the EastGRIP camp with rover mission paths colored by surface elevation of the ice as determined from the CIC rover GPS (Haran et al., 2018).

$10 \%$ longer than the shortest path. Coupling angular frequency referencing measurements at the wheel with the signalled speed controllers would easily correct this problem, but the necessary parts were not available during the summer 2017 deployment. We performed several traction tests to evaluate the predicted rover resistance against measured values. We carried out these tests by loading a sled with different weights and measuring the towing force with a digital spring scale. We found that, on average, the rover encounters a dimensionless resistance, $\frac{R}{F_{\mathrm{g}}}=0.14$, which reached a maximum value of $\frac{R}{F_{\mathrm{g}}}=0.4$, when driving over a field of rippling sastrugi.

To evaluate the capability of the rover to autonomously take photographs that could be subsequently processed to create digital elevation models via structure-from-motion photogrammetry, we installed a DLSR camera on the top of the chassis (Nikon D3000). We signalled the camera from the microcontroller using one of the Arduino MEGA's four serial channels. Because the instrument sampling frequency for the SfM camera and drive correction interrupt frequencies are much smaller than the quartz oscillator on the microcontroller, the instrument signalling does not conflict with navigation and is unimpaired by the processing speed of the microcontroller. Instruments that require high-precision triggering, such as radar receivers, would need to externally stack and $\log$ data to prevent disrupted acquisition due to falsely triggered pulses from the Arduino, which cannot write fast enough to trigger, record, and stack received radar pulses.

The camera (Nikon D3000) mounted to the rover was triggered to take one picture every second as the rover passed by a region outside of the EastGRIP camp that was manually monitored for accumulation by measuring elevation height change relative to 200 wooden poles. We used these photos to construct digital elevation models of the snow surface 

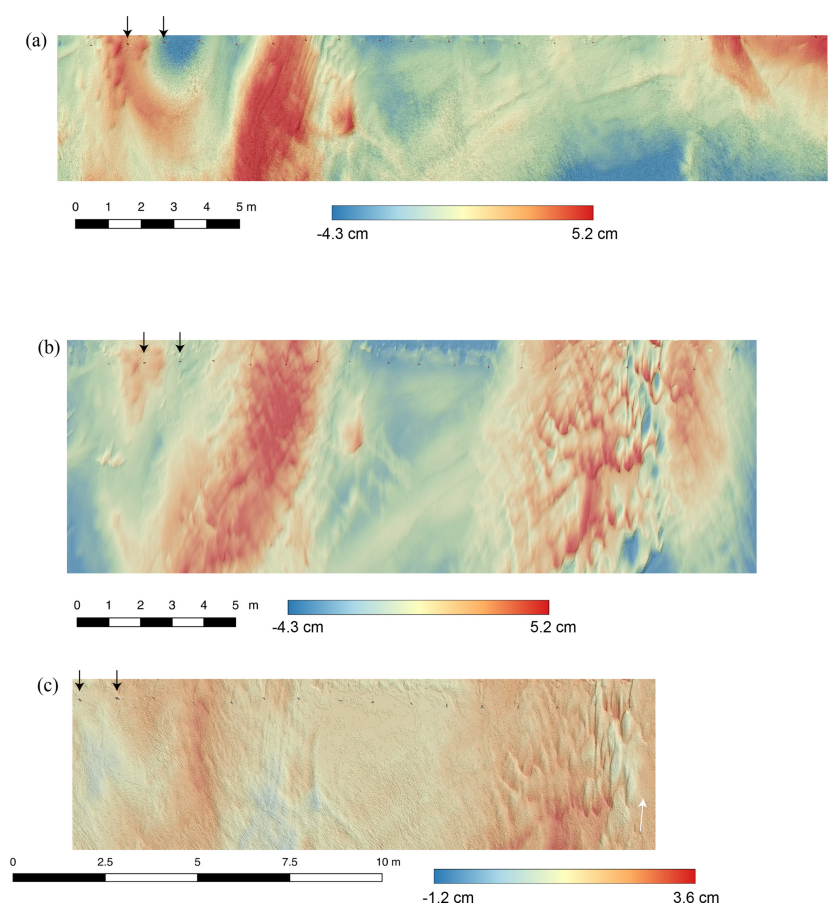

Figure 4. Relative snow surface height in the region monitored for accumulation. Panel (a) shows the surface height on 19 July before a storm system swept through the EastGRIP camp on 20 July, and panel (b) shows the surface height on 22 July after the storm. Black arrows in upper left corner of each panel indicate the first two poles in the row of accumulation monitoring sites. (c) Snow height difference between digital elevation models from 19 and 22 July measured from the top of the poles inferred to be accumulation during the storm. The white arrow indicates prevailing wind direction during the storm.

via SfM photogrammetry. SfM photogrammetric processing triangulates the position of co-imaged snow features from multiple photographs to create a Cartesian point cloud of the measured surface. The point cloud can then be gridded into a 3-D relative digital elevation model (DEM) by interpolating different samples of points and comparing their misfit to create a map of relative elevation and elevation uncertainty. We used the Agisoft PhotoScan structure-from-motion (SfM) algorithm (Koenderink and Doorn, 1991; Westoby et al., 2012) to process 50 photos taken by the rover in the first $25 \mathrm{~m}$ of this site on 19 and 22 July. In our photogrammetric analysis, we assume that the poles referenced to monitor accumulation do not move relative to one another and represent faithful markers of unchanged position in the Lagrangian reference frame of the moving ice. This assumption is already made in typical manual measurements, which use changes in height from the top of the stake to the surface to infer accumulation change. However, in our elevation maps, we see that the poles themselves change the pattern of local surface height so that relative elevation measurements at the poles cannot resolve millimeter-scale changes in surface height (Fig. 4). Outside

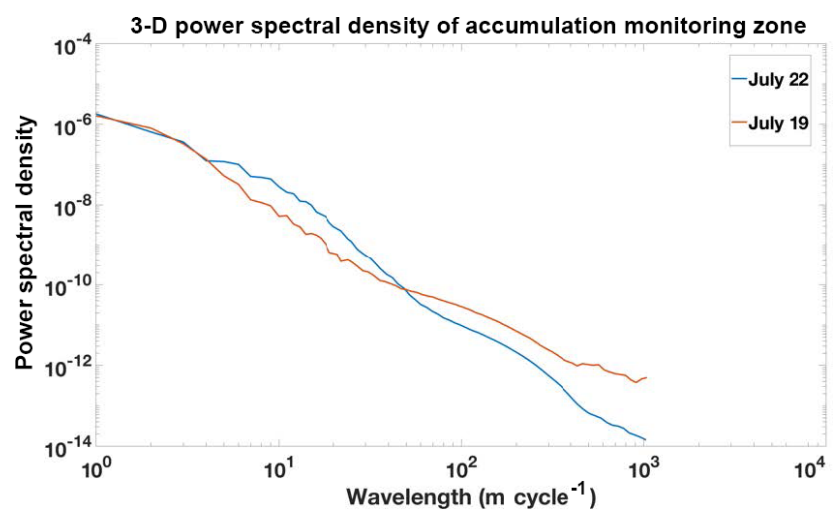

Figure 5. Power spectral density periodogram of the region of snow accumulation taken from the rover before and after the storm. The power changes from low frequency to high frequency after the high wind speeds sculpt steeper, shorter wavelength sastrugi.

of the region monitored for accumulation, where there are no snow-free markers to difference elevation models, we can use the rover precision GPS to establish referenced camera positions and camera angles. In this framework, map precision depends on the co-registration of features across photos and also on the uncertainty of the camera position calculated from the GPS. We report our precision as $\pm 95 \%$ of the root-mean-square error of the elevation difference between the two digital elevation models (DEM) after they have been optimally co-registered to the accumulation poles. Overall, these maps measure relative elevation with an accuracy better than $1 \mathrm{~cm}$ and precision better than $4 \mathrm{~mm}$. To ensure that the difference along the stake row is faithful to the existing measurements for accumulation, each stake is compared to stake heights measured manually, which match within the tolerance of error except where the poles created significant depressions in the surface and the relative height between the surface and the top of the pole is more ambiguous. The distribution of poles is not completely uniform, so we can use the misalignment of the row of poles to our advantage to find the single affine translation that best aligns the elevation models. We then difference our DEMs to determine accumulation due to drifting and snow fall between the two image acquisition periods.

After the storm, we find higher amplitude finer wavelength features $(0.5-2 \mathrm{~m})$. Wind speeds rose from 0 to $2 \mathrm{~m} \mathrm{~s}^{-1}$ before the storm to over $10 \mathrm{~m} \mathrm{~s}^{-1}$ during the seven-hour storm, causing a transition in dominant snow grain transport process from creep-dominated snow bedform evolution to saltation of grains and the formation of finer sastrugi. These smallscale features diffuse away as wind speeds fall below the threshold velocity required to maintain their steeper slopes (Filhol and Sturn, 2015) so that the surface eventually resembles the roughness we record before the storm. In future iterations of this low-cost rover, real-time processing of atmospheric data could feedback into the drive control soft- 
ware to allow adaptive driving over an evolving surface with a roughness that is highly dependent on the recent precipitation and local wind speed history.

\section{Discussion}

The CIC rover deployed as part of the summer 2017 EastGRIP field campaign fulfilled the initial science goal to develop a modular, inexpensive platform capable of investigating remote regions tens of kilometers away from centralized camp resources. Because the platform is ground-based, it is extremely stable, and can carry over $20 \mathrm{~kg}$ of additional instrument weight in its chassis and over $100 \mathrm{~kg}$ of weight in a sled. The rover is also emission free, allowing it to cleanly sample the near-surface atmospheric boundary layer important for quantifying water vapor exchanges between the snow surface and the atmosphere, and to sample the snow surface directly for snow microstructure and snow specific surface area measurements. The schematics for building the rover are freely available, are easy for new developers to follow and modify, and include total costs of the rover build including import duties, taxes, and fees. Not all of these design strengths are unique to the CIC rover, and we therefore focus our remaining evaluation of rover performance on the advantages and disadvantages of using modular, inexpensive rover systems compared with more sophisticated platforms (Lever et al., 2013).

The obvious advantage of the low-cost platform is the savings that could be used to instrument the rover or expand deployment scope and logistical support. Secondary advantages come as a result of the expendability of low-cost designs, which can be sent to more hazardous field sites such as ice-stream shear margins or crevassed ice shelves. If parts of the drive system break or the rover falls into a crevasse, new rover parts can be printed, and inexpensive auxiliary parts furnished for a replacement rover. The ability to build and fix the rover quickly also aids in-field rover redesign. During the July 2017 deployment, we were able to fix the rover in response to shortcomings we had not foreseen before the field season. The internal width of the rover tires shrank in the cold, meaning that, in drifted snow, the force needed to overcome the frictional force of sinkage became greater than the traction between the tire carcass and the wheel rim. Occasionally, this would cause the wheel rim to spin freely inside the tire carcass, wearing away part of the tire and exacerbating the tire-rim misfit. Our 3-D printable rim design allowed us to print new rims $1 \mathrm{~cm}$ wider, increasing the traction between the hub and the tire wall and allowing the rover to continue surveying effectively. The data collection for the 2017 field season exceeded the expected scientific yield of the lowcost rover prototype, but also highlighted several barriers for extending low-budget rover operations beyond the scope of localized GPS and photogrammetric surveys. Low-cost rovers fitted with more valuable instruments such as ground- penetrating radar capable of imaging crevasses, come at the cost of rover system expendability. To locate crevasses in hazardous high-strain ice-sheet environments the originally low-cost rover must be outfitted with expensive software and instruments that increase the value of the coupled platform. Enhancing rover autonomy and the area of rover coverage further complicates rover development. Costs to manufacture sophisticated polar rovers are similar to the cost of flying from logistical hubs near the ice-sheet coasts to the deep ice-sheet interior; this makes the total cost to manufacture and ship an inexpensive rover to the Greenland interior only marginally less expensive than the combined cost of building and shipping a more sophisticated platform. Science and logistical budgets often tap different resources, but this remains an obvious weakness. Inexpensive polar rovers could be designed to traverse into interior areas of interest from coastal stations and back again, but traversing hundreds of kilometers requires harnessing solar or wind power, substantially reducing system simplicity. A possible solution could leverage existing deep field battery stores, remotely charging rovers with existing infrastructure. These modified deep field rovers would autonomously dock to charging stations that are slowly buried with snow over the course of a year, but this could be an inexpensive means of simultaneously monitoring remote battery drainage while leveraging existing resources for targeted surveys near convenient polar weather stations and GPS/seismic sites. Deploying charging stations with battery stores for existing automatic atmospheric or geophysical observation sites in the deep field in Greenland and Antarctica is currently outside the scope of our science capabilities, but we hope to demonstrate the feasibility of such a system for rover tests in Washington's Cascadia glaciers in the future.

\subsection{Future development}

We will take an incremental approach towards further developing low-cost polar rovers. This strategy will significantly increase the complexity of the rover but will aim to add modular sophistication with additions to the power bus and communication board that could be replaced or removed easily without compromising the basic drive mechanics and sampling capabilities of the existing rover design. Future iterations of our rover's power system will include modules for solar panels and cold-weather wind turbines designed to address the limitations of the rover's power system, extending coverage from tens of kilometers to hundreds of kilometers. These improvements will be combined with the development of a charging station, which the rover can autonomously dock to and power if the station batteries are low or charge from when surplus power is available. We will also redesign the rover's communication software to enable data transmission and reception over radio frequencies leveraging the modular strengths of the existing rover design to enable larger-scale multi-rover data collection campaigns. With the addition of 
UHF inter-rover radio communication, rovers could be coordinated to map high-resolution strain patterns in poorly sampled regions of the ice-sheet (GPS surveying near the satellite pole hole for instance) and internal layers (via groundpenetrating radar) along repeatable tracks. A linked network of rovers equipped with ground-penetrating radar would also allow real-time radar survey design to densify sampling in areas where internal layers anomalously dim or vanish, where the bed reflector dims or brightens, or where cross-track and off-nadir reflections between rovers disagree. In the future, we plan to use these improved rovers to make repeat annual radar measurements to enhance understanding of how ice flow affects the internal layers of the ice sheet in regions of fast flow, such as the Northeast Greenland Ice Stream shear margins.

\section{Conclusions}

The development of the CIC rover was motivated by our goal to design an autonomous rover platform for hazardous and power-limited remote sensing of the Earth's ice sheets. This set our design considerations: to make a research platform that will conserve field resources and extend the range of data collection to dangerous, isolated ice-sheet regions that go undersampled due to the threat of crevasses, severe weather, or simply their remote location. We have demonstrated the versatility, durability, and value of the CIC platform through test deployments in northeast Greenland out of the EastGRIP camp. When our printed parts (chassis and rims) were damaged, a repaired rover using new printed parts was redeployed after just $1 \mathrm{~d}$. Components that cannot be printed (e.g., batteries, motors, and microcontrollers) are modular, allowing for easy replacement, if damaged, and specialization depending on rover use. Future rover design efforts will focus on adding a solar panel array and charging station that leverages the polar summer's abundant solar power availability to extend the rover's range from tens to hundreds of kilometers, and the integration of instruments into a now proven rover platform. The rover's success demonstrates that semiautonomous polar instruments can be built at very low costs, opening up new measurement campaign possibilities that involve several platforms that conduct linked surface science simultaneously.

Data availability. The rover navigational code and data that we collected at EastGRIP (GPS positions, and digital elevation models) will be available on the UW ResearchWorks digital repository in the near future (https://digital.lib.washington.edu/researchworks/, last access: 2 June 2019). In the meantime, the data can be made available upon request from the corresponding author (hoffmaao@uw.edu).
Supplement. The supplement related to this article is available online at: https://doi.org/10.5194/gi-8-149-2019-supplement.

Author contributions. AH designed and constructed the rover with help from the CIC workshop, and developed and carried out the field experiments at EastGRIP. HC, S-L and $\mathrm{CH}$ provided valuable feedback on the rover design. $\mathrm{AH}$ and $\mathrm{KC}$ processed rover GNSS and photogrammetry data. AH was the lead author of the paper with input from all co-authors. $\mathrm{AH}$ and $\mathrm{KC}$ drafted the figures.

Competing interests. The authors declare that they have no conflict of interest.

Acknowledgements. This work was supported by research grants (grant nos. 2361 and 16572) from VILLUM FONDEN. Logistical support was provided by the East Greenland Ice-Core Project. EastGRIP is directed and organized by the Center of Ice and Climate at the Niels Bohr Institute. It is supported by funding agencies and institutions in Denmark (A. P. Møller Foundation, University of Copenhagen), the USA (U.S. National Science Foundation, Office of Polar Programs), Germany (Alfred Wegener Institute, Helmholtz Centre for Polar and Marine Research), Japan (National Institute of Polar Research and Arctic Challenge for Sustainability), Norway (University of Bergen and Bergen Research Foundation), Switzerland (Swiss National Science Foundation), France (French Polar Institute Paul-Emile Victor, Institute for Geosciences and Environmental research), and China (Chinese Academy of Sciences and Beijing Normal University). We thank Karl-Emil and the NBI workshop for their help in the rover design process. The authors thank two anonymous reviewers for their comments, which substantially improved this paper.

Financial support. This research has been supported by the VILLUM FONDEN (grant no. 2361/16572).

Review statement. This paper was edited by Francesco Soldovieri and reviewed by two anonymous referees.

\section{References}

Army Corps of Engineers: Tracks versus wheels in soft soil and snow, Miscellaeous paper No. 4-651, 1972.

Baltsavias, E., Favey, E., Bauder, A., Bosch, H., and Pateraki, M.: Digital Surface Modelling by airborne laser scanning and digtal pho5 togrammetry for glacier monitoring, Photogramm. Rec., 17, 243-273, 2001.

Behar, A., Mattews, J., Carsey, F., and Jones, J.: NASA/JPL Tumbleweed Polar Rover, IEEE Aerospace Conference, 6-13 March 2004 in Big Sky, Mt, USA, 2004.

Bekker, M.: Mechanics of Off-the-Road Locomotion, Proc. Instit. Mechan. Eng., 16, 25-44, 1962. 
Blitch , J. G.: Semi-autonomous tactical robots for urban operations, IEEE International Symposium on Intelligent Control (ISIC), Gaithersburg, MD, USA, September, 1998.

Department of Defense U.S.: Unmanned systems integrated roadmap FY2013-2038, 2013.

Filhol, S. and Sturm, M.: Snow bedforms: A review, new data, and a formation model, J. Geophys. Res.-Earth Surf., 120, 1645-1669, 2015.

Haran, T., Bohlander, J., Scambos, T., Painter, T., and Fahnestock, M.: MEaSUREs MODIS Mosaic of Greenland (MOG) 2005, 2010, and 2015 Image Maps, Version 2. [Indicate subset used], Boulder, Colorado USA, NSIDC: National Snow and Ice Data Center, https://doi.org/10.5067/9ZO79PHOTYE5, September 2018.

Ishigami, G., Miwa, A., Nagatani, K., and Yoshida, K.: Terramechanics-Based Model for Steering Maneuver of Planetary Exploration Rovers on Loose Soil, J. Field Robot., 24, 233 250, 2007.

Koenderink, J. and Doorn, A. V.: Affine structure from motion, JOSA A, 8, 377-385, 1991

Lever, J., Denton, D., Phetteplace, G., Wood, S., and Shoop, S.: Mobility of a lightweight tracked robot over deep snow, J. Terramechan., 43, 527-551, 2006.

Lever, J., Delaney, A., Ray, L., Trautmann, E., Barna, L., and Burzynski, A.: Autonomous GPR Surveys using the Polar Rover Yeti, J. 20 Field Robot., 30, 194-215, 2013.
Maddux, G. A., Bosco, C. D., and Lawrence, J. D.: Integration of unmanned systems for tactical operations within hostile environments, DEFENSE AND SECURITY SYMPOSIUM, Unmanned Systems Technology VIII, 6230, 2006.

Ray, L., Lever, J., Streeter, A., and Price, A.: Design and Power Management of a Solar-Powered "Cool Robot" for Polar Instrument Net25 works, J. Field Robot., 24, 581-599, 2007.

Robertson, M. E., Koenig, L., Trisca, G., and Marshall, H.: Accumulation mapping at Summit, Greenland using an autonomous rover, American Geophysical Union, Fall Meeting, San Francisco, CA, USA, December, 2013.

Trisca, G. O., Robertson, M. E., Marshall, H., Koenig, L., and Comberiate, M. A.: GROVER: An autonomous vehicle for ice sheet research, American Geophysical Union, Fall Meeting, San Francisco, CA, USA, December, 2013.

Weisbin, C., Blitch, J., Lavery, D., Krotkov, E., Shoemaker, C., Matthies, L., and Rodriguez, G.: Miniature robots for space and military missions, IEEE Robotics \& Automation Magazine, 6, 9-18, 1999.

Westoby, M., Brasington, J., Glasser, N., Hambrey, M., and Reynolds, J.: Structure-from-Motion photogrammetry: a lowcost, effective tool for geoscience applications, Geomorphology, 179, 300-314, 2012. 